\author{
Camila Duane Corrêa Gaia ${ }^{1 *}$ (D) \\ Italo Marlone Gomes Sampaio ${ }^{2}$ (D) \\ Mariele dos Santos Araújo ${ }^{2}$ (iD \\ Jéssica Mariana Coelho Magalhães ${ }^{1}$ (D) \\ Raquel Giselli Assis Rosário ${ }^{2}$ (D) \\ Rodrigo Otávio Rodrigues de \\ Melo Souza ${ }^{2}$ (iD
}

${ }^{1}$ Universidade Estadual Paulista (Unesp), Rua José Barbosa de Barros, 1780, 18.610-307, Botucatu, SP, Brazil.

${ }^{2}$ Universidade Rural da Amazônia (Ufra), Instituto de Ciências Agrárias (ICA), Avenida Presidente Tancredo Neves, 2501 66.077-830, Belém, PA, Brazil.

*Autor correspondente:

E-mail: camilagaia7@gmail.com

\section{PALAVRAS-CHAVE}

Acmella oleracea

Eficiência no uso da água

Manejo da irrigação

\section{KEYWORDS}

Acmella oleracea

Water use efficiency

Irrigation management

\title{
Crescimento e produção do jambu submetido a lâminas de irrigação
}

\author{
Growth and crop production of jambu under various \\ irrigation depths
}

RESUMO: O objetivo deste trabalho foi avaliar o efeito de diferentes lâminas de irrigação no crescimento e produção de plantas de jambu. Os tratamentos consistiram de cinco lâminas de irrigação correspondentes a $40 \%, 70 \%, 100 \%, 130 \%$ e $160 \%$ da capacidade de campo. O delineamento experimental foi em blocos casualizados com quatro repetições. A parcela foi constituída por quatro plantas em vasos separados. Para efeito de comparação dos tratamentos, 27 dias após o transplantio, foram analisadas as seguintes variáveis: comprimento da parte aérea, diâmetro da haste, massa fresca de folhas, massa fresca de caule, massa fresca de raiz, massa fresca das inflorescências, massa seca de folhas, massa seca de caule, massa seca de raiz, massa seca das inflorescências e eficiência do uso de água. O efeito das lâminas foi significativo para todas as variáveis analisadas exceto o diâmetro da haste e a massa seca das inflorescências. Houve comportamento quadrático para a maioria das variáveis em relação às lâminas de irrigação aplicadas. Os valores máximos de cada parâmetro foram obtidos com lâminas próximas à lâmina de $100 \%$ da capacidade de campo. Embora a eficiência da utilização de água tenha sido maior para a lâmina de $40 \%$ da capacidade de campo, o mais recomendado é utilizar a de $100 \%$ da capacidade de campo, pois esta proporcionou as melhores respostas nas variáveis analisadas.

ABSTRACT: This study evaluated the effect that different irrigation depths have on the growth and crop production of jambu plants. The treatments consisted of five irrigation depths corresponding to $40 \%, 70 \%, 100 \%, 130 \%$ and $160 \%$ of field capacity. We used randomized blocks with four replications for the experimental design. The plot consisted of four plants in separate pots. For comparison of treatments, at 27 days after transplantation, the following variables were analyzed: plant height, stem diameter, leaffresh matter, stalk fresh matter, root fresh matter, inflorescence fresh matter, leaf dry matter, stalk dry matter, root dry matter, inflorescence dry matter and water use efficiency. The effect of irrigation depth was significant for the analyzed variables, except for stem diameter and inflorescence dry matter. There was a quadratic behavior of the variables regarding the applied irrigation depths. The maximum values of each parameter were obtained with irrigation depths close to $100 \%$ field capacity. Although the efficiency of water use was higher for the irrigation depth of $40 \%$ field capacity, the use of irrigation depth at 100\% field capacity is recommended since it provided the best answers of the variables analyzed. 


\section{Introdução}

O jambu (Acmella oleracea (L.) R.K. Jansen) é considerado uma importante hortaliça da região Amazônica, principalmente no Pará, devido ao seu papel na cultura, gastronomia e medicina popular da região. Pertencente à família Asteraceae, é uma planta herbácea com 20 a $30 \mathrm{~cm}$ de altura, possui caule cilíndrico, carnoso decumbente e ramificado. A inflorescência é um capítulo globoso terminal (Gusmão \& Gusmão, 2013).

É uma hortaliça de grande interesse para as empresas farmacêuticas e de cosméticos devido às propriedades químicas associada a um composto bioativo conhecido como espilantol presente nas folhas, hastes e inflorescências da planta (Barbosa et al., 2016). Devido a isso tem ocorrido expansão do seu cultivo no Brasil, como por exemplo, nos Estados do Rio de Janeiro, São Paulo, Minas Gerais e Piauí. Em São Paulo, a produção de jambu é direcionada exclusivamente para a extração de óleo essencial, afim de explorar as potencialidades de seus bioativos (Borges et al., 2014), fato este que diverge de regiões como o Estado do Pará cuja produção é direcionada para o consumo em pratos típicos (Sampaio et al., 2018).

No Pará, a produção de jambu para abastecimento da Região Metropolitana de Belém ocorre nos municípios próximos, como Ananindeua, Benevides, Santa Izabel do Pará e Santo Antônio do Tauá (Homma et al., 2011; Gusmão \& Gusmão, 2013). Essa hortaliça representa importante fonte de renda para os pequenos produtores dos municípios do Estado do Pará (Homma et al., 2014). Ela também está presente em outros estados da Região Norte, como o Acre, Amazonas e Amapá (Silva et al., 2020).

Apesar da expansão do cultivo e de estudos a respeito das propriedades farmacológicas do jambu, pouco se sabe sobre sua demanda hídrica, pois existe uma carência de informações fitotécnicas sobre a cultura, porém, recentes trabalhos têm discutidos melhorias em seu sistema produtivo (Sampaio et al., 2018; Sampaio et al., 2019). Embora encontre-se na literatura trabalhos como o de Aviz et al. (2019) dando enfoque quanto à resposta positiva do jambu ao suprimento adequado de água, de maneira geral não há dados atualizados sobre a gestão de água nas propriedades onde se cultiva jambu. Na realidade, as informações acerca da agricultura irrigada no Estado do Pará ainda são pouco difundidas (Souza et al., 2012).

Assim sendo, estudos que apresentem características de utilização de água e de necessidade hídrica do jambu podem auxiliar na melhoria dos sistemas de produção da espécie já existentes, bem como na realização do manejo da irrigação e da eficiência do uso da água. Entre outras questões, o manejo adequado da irrigação é importante não apenas para suprir a demanda hídrica da cultura, mas para a redução do custo operacional, de problemas fitossanitários e desperdício de fertilizantes (Koetz et al., 2006).

Com base no exposto e como forma de orientar os produtores a reduzir o desperdício de água, melhorando a gestão dos recursos hídricos de suas propriedades, e suprir a falta de informação em relação a cultura do jambu, este trabalho teve como objetivo avaliar o efeito de diferentes lâminas de irrigação no crescimento e produção da cultura.

\section{Material e métodos}

O trabalho foi realizado no Instituto de Ciências Agrárias da Universidade Federal Rural da Amazônia, Campus Belém (ICA-Ufra) no período de 23 de novembro de 2017 a $1^{\circ}$ de fevereiro de 2018 em casa de vegetação do tipo capela com semi-lanternim, coberta com polietileno de $100 \mu \mathrm{m}$ tratado contra radiação UV, com pé direito inferior de 2,25 m e superior de 3,5 m e laterais com tela de arame galvanizado de $40 \mathrm{~mm}$.

$\mathrm{O}$ delineamento experimental foi em blocos casualizados com quatro repetições. Os tratamentos foram constituídos de cinco diferentes lâminas de irrigação $(40 \%, 70 \%, 100 \%, 130 \%$ e $160 \%$ da capacidade de campo). A parcela foi constituída por quatro plantas cultivadas em vasos separados.

A variedade de jambu (Acmella oleracea (L.) R.K. Jansen) utilizada foi a variedade flor roxa (Gusmão \& Gusmão, 2013) obtida na horta vinculada ao ICA, cujas coordenadas são $01^{\circ} 27^{\prime} 19^{\prime \prime} \mathrm{S}$ e $48^{\circ} 26^{\prime} 20^{\prime \prime} \mathrm{O}$. O clima é classificado com Afi de acordo com a classificação de Köppen (Alvares et al., 2013).

As mudas foram produzidas em bandejas de poliestireno (Isopor) de 128 células preenchidas com substrato a base de composto orgânico obtido a partir da compostagem de capins, folhas e esterco bovino. Em seguida, foi realizada a semeadura na densidade de seis sementes (aquênios) por célula. Após a germinação, as bandejas foram transferidas para bancadas, onde foram mantidas em sistema de fertirrigação subsuperficial até o transplantio, que foi realizado com 20 dias após germinação. Com sete dias após a germinação ocorreu o desbaste, deixando-se uma planta por célula. Utilizou-se para fertirrigação a formulação proposta por Furlani et al. (1999) para hortaliças folhosas ajustada a $50 \%$ da força iônica para macronutrientes.

Utilizou-se vasos com capacidade de $3 \mathrm{~L}$, tendo as seguintes dimensões: $16 \mathrm{~cm}$ de altura x $18 \mathrm{~cm}$ de diâmetro, totalizando um volume de $0,00407 \mathrm{~m}^{3}$. O substrato utilizado foi solo misturado com composto orgânico (à base de capins, folhas e esterco bovino) na proporção $3: 1$, cuja caracterização química está descrita na Tabela 1, obtida conforme metodologia de Silva (2009). Antes do preenchimento do vaso o substrato foi seco em estufa e peneirado. Foi transplantada uma muda de jambu em cada vaso.

Tabela 1. Resultado da análise química do substrato (solo e composto orgânico) utilizado.

Table 1. Result of chemical analysis of the used substrate (soil e organic compost).

\begin{tabular}{|c|c|c|c|c|c|c|c|c|c|c|c|}
\hline $\mathrm{pH}_{\mathrm{H} 2 \mathrm{O}}$ & $\mathrm{Ca}$ & $\mathrm{Mg}$ & $\mathrm{Al}$ & & $\begin{array}{l}\mathrm{H}+\mathrm{Al} \\
\mathrm{lm}^{-3}\end{array}$ & SB & $\mathrm{t}$ & $\mathrm{T}$ & $\mathrm{V} \%$ & $\mathrm{~m} \%$ & $\begin{array}{c}\mathrm{P} \\
\mathrm{mg} \mathrm{kg}^{-1}\end{array}$ \\
\hline 4,5 & 6,0 & 2,3 & 0,4 & 0,3 & 13,5 & 8,7 & 9,1 & 22,2 & 39,1 & 4,4 & 10,6 \\
\hline
\end{tabular}


A adubação de cobertura consistiu no uso de $40 \mathrm{mg}$ de ureia por vaso e aplicação de biofertilizante (a base de esterco de carneiro) por via foliar, diluindo-se $1 \mathrm{~L}$ de biofertilizante em $5 \mathrm{~L}$ de água, com periodicidade semanal. Utilizou-se cerca de $6,25 \mathrm{ml}$ por planta. O biofertilizante foi produzido a partir da fermentação anaeróbica da mistura de $20 \mathrm{~kg}$ de esterco de carneiro $+40 \mathrm{Lde}$ água seguindo recomendações de Sampaio et al. (2016).

A capacidade de campo foi determinada por meio do método gravimétrico, desenvolvido por Klar et al. (1966). Inicialmente, foram secos 2,5 $\mathrm{kg}$ de substrato de cinco amostras até atingir massa constante. Após isso, as amostras foram colocadas nos seus respectivos vasos e saturadas com água. Em seguida foram dispostos em uma bancada feita de arames trançados, onde foi possível observar a drenagem do excesso de água. Após ser observado que a drenagem cessou, os vasos foram pesados. A diferença entre a massa do conjunto vaso com substrato na capacidade máxima de retenção de água e vaso com solo seco, resultou na quantidade de água necessária para atingir a capacidade de campo do vaso.

A massa média do solo seco e do substrato na capacidade de campo foi de 2,1912 kg e 3,1784 kg, respectivamente. A partir da diferença dessas duas massas foram atribuídas as porcentagens para cada lâmina de irrigação desejada $(40 \%, 70 \%, 100 \%, 130 \%$ e $160 \%$ da capacidade de campo do vaso), que somadas a massa do solo seco resultou na massa de referência para cada tratamento, conforme a Tabela 2.

Tabela 2. Massa de referência para cada lâmina de irrigação utilizada no experimento.

Table 2. Reference mass for each irrigation depth used in the experiment.

\begin{tabular}{cc}
\hline Tratamento & Massa de referência $(\mathrm{kg})$ \\
\hline $40 \%$ & 2,5861 \\
$70 \%$ & 2,8820 \\
$100 \%$ & 3,1784 \\
$130 \%$ & 3,4746 \\
$160 \%$ & 3,7710 \\
\hline
\end{tabular}

As porcentagens utilizadas no tratamento das lâminas de irrigação foram assim determinadas com o objetivo de conhecer o comportamento da cultura sob condições de baixa e alta umidade no solo. Foi considerado como tratamento controle a umidade de $100 \%$ da capacidade de campo. A partir desta, foram estabelecidos dois tratamentos acima e dois abaixo.

A irrigação foi realizada por meio da utilização de gotejadores autocompensantes da Netafim, que trabalham na vazão média de $1,9 \mathrm{~L} \mathrm{~h}^{-1}$, dentro da faixa de pressão de 0,5 a 4 bar. Foi utilizado um emissor autocompensante por vaso. Foi realizada a avaliação hidráulica do sistema de irrigação utilizado, que apresentou uniformidade de distribuição de $95,77 \%$, sendo classificado como excelente, de acordo com Mantovani (2001). A avaliação hidráulica seguiu as recomendações de Keller e Karmeli (1975), conforme equação 1:

$$
\mathrm{CUD}=\frac{\mathrm{q} 25 \%}{\mathrm{qmed}}(1)
$$

em que: CUD - Coeficiente de Uniformidade de Distribuição; q25\% - Média de 25\% das menores vazões coletadas $\left(\mathrm{L} \mathrm{h}^{-1}\right)$; qmed - média de todas as vazões coletadas.

Para determinação do tempo de irrigação necessário para a reposição da quantidade de água para cada tratamento, quatro vasos foram pesados diariamente. O volume de água necessário para cada tratamento foi calculado a partir da diferença entre a massa de referência das lâminas de irrigação (Tabela 1) e a massa atual dos vasos no dia analisado e, quando necessário, realizou-se a irrigação.

Para efeito de comparação dos tratamentos, aos 27 dias após o transplantio, foram analisadas as seguintes variáveis: comprimento da parte aérea $(\mathrm{CPA} ; \mathrm{cm})$, diâmetro da haste $(\mathrm{DH}$; $\mathrm{mm}$ ), massa fresca de folhas (MFF; $\mathrm{g} \mathrm{planta}^{-1}$ ), massa fresca de caule (MFC; $g_{\text {planta }}{ }^{-1}$ ), massa fresca de raiz (MFR; g planta ${ }^{-1}$ ), massa fresca das inflorescências (MFI; g planta ${ }^{-1}$ ), massa seca de folhas (MSF; g planta ${ }^{-1}$ ), massa seca de caule (MSC; g planta $^{-1}$ ), massa seca de raiz (MSR; g planta ${ }^{-1}$ ), massa seca das inflorescências (MSI; $g$ planta ${ }^{-1}$ ) e eficiência do uso de água (EUA; g planta ${ }^{-1} \mathrm{~mm}^{-1}$ ), obtida através da Equação 2.

$$
\mathrm{EUA}=\frac{\mathrm{P}}{\mathrm{L}}(2)
$$

em que: EUA - Eficiência do uso de água $\left(\mathrm{g} \mathrm{mm}^{-1}\right) ; \mathrm{P}$ - é a produção de massa fresca da parte aérea (inflorescências, folhas e caule) ( $\mathrm{g} \mathrm{planta}^{-1}$ ); L - Lâmina total aplicada ( $\mathrm{mm})$.

O CPA foi obtido por meio da utilização de régua graduada. O DH foi medido com o auxílio do paquímetro digital. Todas as massas frescas e secas da planta foram determinadas por meio de balança semianalítica com precisão de 0,001 g. Para a obtenção da massa seca foi utilizada uma estufa com circulação forçada de ar, mantendo-se a temperatura em $65 \pm 5^{\circ} \mathrm{C}$ por 72 horas.

Os resultados obtidos foram submetidos a análise de variância pelo teste F. Quando significativo, foi realizada análise de regressão. As análises foram processadas por meio do programa estatístico Sisvar 5.6 (Ferreira, 2011).

\section{Resultados e discussão}

As lâminas acumuladas e médias resultaram nos valores descritos na Tabela 3. Observa-se diferenças acentuadas dos valores de lâminas de irrigação da aplicação dos tratamentos. Tendo-se como base a lâmina de $100 \%$ da capacidade campo do substrato, verifica-se que esta foi aproximadamente 18 vezes superior à lâmina aplicada no tratamento de $40 \%$, o que representou uma ampla variação no teor de água no solo para o crescimento e desenvolvimento da cultura do jambu. 
Tabela 3. Lâminas de irrigação aplicadas na cultura do jambu em cada tratamento.

Table 3. Irrigation depths applied to jambu crop in each treatment.

\begin{tabular}{ccc}
\hline Tratamento & $\begin{array}{c}\text { Lâmina média } \\
\left(\mathrm{mm} \mathrm{dia}^{-1}\right)\end{array}$ & Lâmina Total $(\mathrm{mm})$ \\
\hline $40 \%$ & 0,36 & 9,61 \\
$70 \%$ & 1,32 & 35,69 \\
$100 \%$ & 6,40 & 172,68 \\
$130 \%$ & 18,82 & 508,18 \\
$160 \%$ & 27,72 & 748,50 \\
\hline
\end{tabular}

As lâminas de irrigação apresentaram diferença significativa $(p<0,05)$ nas variáveis morfológicas avaliadas, a exceção do DH e MSI. Em geral, o comportamento das variáveis foi explicado por modelo quadrático.

Para o CPA, as lâminas de irrigação promoveram ganhos até certo ponto, a partir do qual, verificou-se redução da parte aérea das plantas, o que foi explicado por uma função quadrática, sendo a maior reposta estimada $(18,41 \mathrm{~cm})$ na lâmina de $100 \%$ (Figura 1).

De forma semelhante ao CPA, as maiores respostas observadas para as variáveis MFF e MSF foram, respectivamente, nas lâminas de 98 e $98,02 \%$, com valores máximo estimados de 8,19 e $0,95 \mathrm{~g}$ planta $^{-1}$, sendo observado decréscimo com a aplicação de lâminas acima destes níveis de capacidade de campo do substrato (Figura 2).

As células que compõem as folhas, bem como outros órgãos das plantas, são dependentes da pressão de turgor para seu crescimento, que por sua vez é influenciada pela quantidade de água presente na planta (volume celular). Existe um balanço funcional entre absorção de água pelas raízes e fotossíntese da parte área da planta, de forma que a parte aérea continua crescendo até o momento que a absorção de água pelas raízes torne-se um fator limitante, da mesma forma, as raízes continuam crescendo até que a sua demanda por fotoassimilados da parte aérea seja igualada pelo suprimento (Taiz et al., 2017). Assim, o acúmulo de biomassa, tanto fresca como seca, promovido por teores hídricos ótimos no solo para cultura do jambu é desejável, pois tanto suas folhas, caule e inflorescências são comercializáveis (Sampaio et al., 2018).

Diferente dos resultados deste trabalho, Araújo et al. (2010) obtiveram uma resposta linear do efeito de crescentes lâminas (20 a 120\% da lâmina evaporada) de irrigação no crescimento e produção de alface cv. Americana (Lactuca sativa L.). No entanto, deve-se ter cuidado com o excesso de água, visto que as hortaliças apresentam sensibilidade ao encharcamento do solo, conforme observado por Silva \& Queiroz (2013), cujo trabalho mostrou que a cultura da alface apresentou reduções na altura, diâmetro do caule e no acúmulo de biomassa sob estresse por excesso hídrico. Assim, tais resultados demonstram que o desempenho das culturas frente a disponibilidade hídrica depende do material genético, condições edafoclimáticas, bem como do sistema de cultivo adotado.

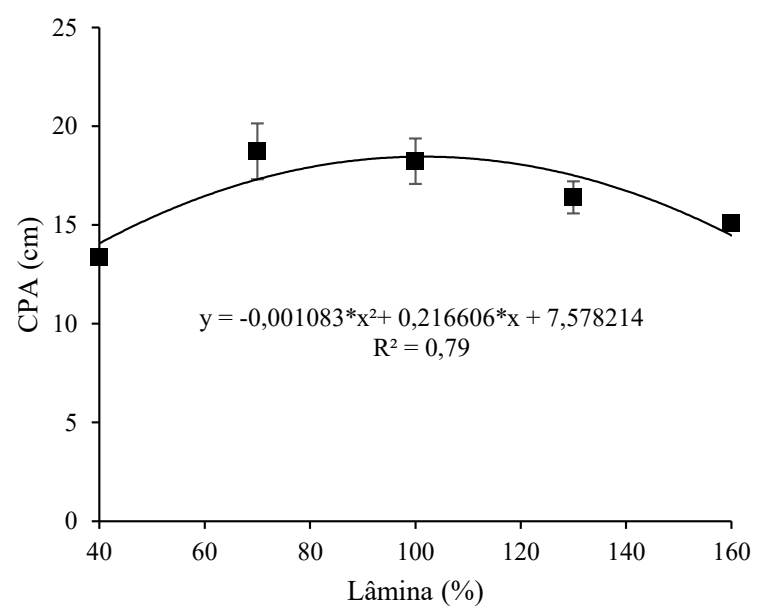

Figura 1. Comprimento da parte aérea de plantas de jambu em função da lâmina de irrigação. ** significativo a $1 \%$ de probabilidade; * significativo a $5 \%$ de probabilidade pelo teste t-Student.

Figure 1. Plant height of jambu crop as a function of irrigation depth. **significant at $1 \%$ probability; *significant at $5 \%$ probability by Student's t-test.

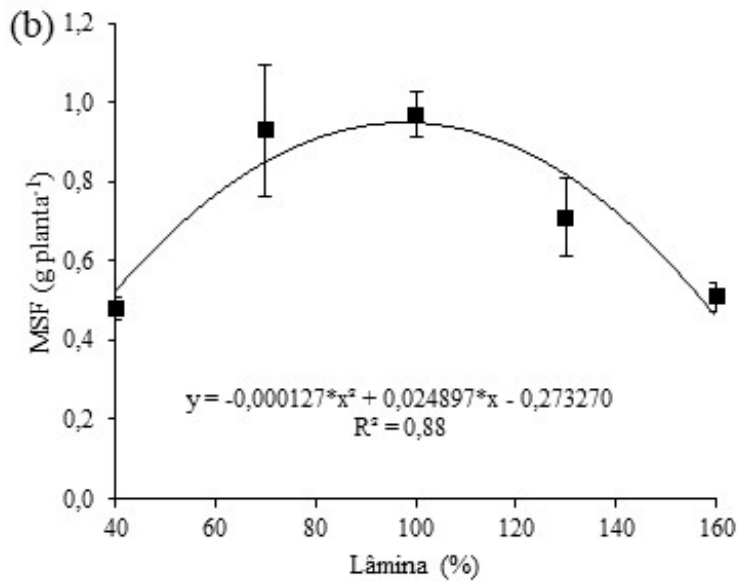

Figura 2. Massa fresca (a) e seca (b) de folhas de plantas de jambu em função da lâmina de irrigação. ** significativo a 1\% de probabilidade; * significativo a $5 \%$ de probabilidade pelo teste t-Student.

Figure 2. Leaf fresh matter (a) and leaf dry matter (b) of jambu crop as a function of irrigation depth. **significant at $1 \%$ probability; *significant at $5 \%$ probability by Student's t-test. 
Os resultados de MFC e MSC foram explicados por modelos quadráticos com valores máximos de 5,81 e 0,48 g planta $^{-1}$ nas lâminas de 94,08 e 94,95\% da capacidade de campo, respectivamente, havendo redução desta variável com aplicação de lâminas acima da capacidade de campo, conforme observado nas variáveis anteriores (Figura 3 ).
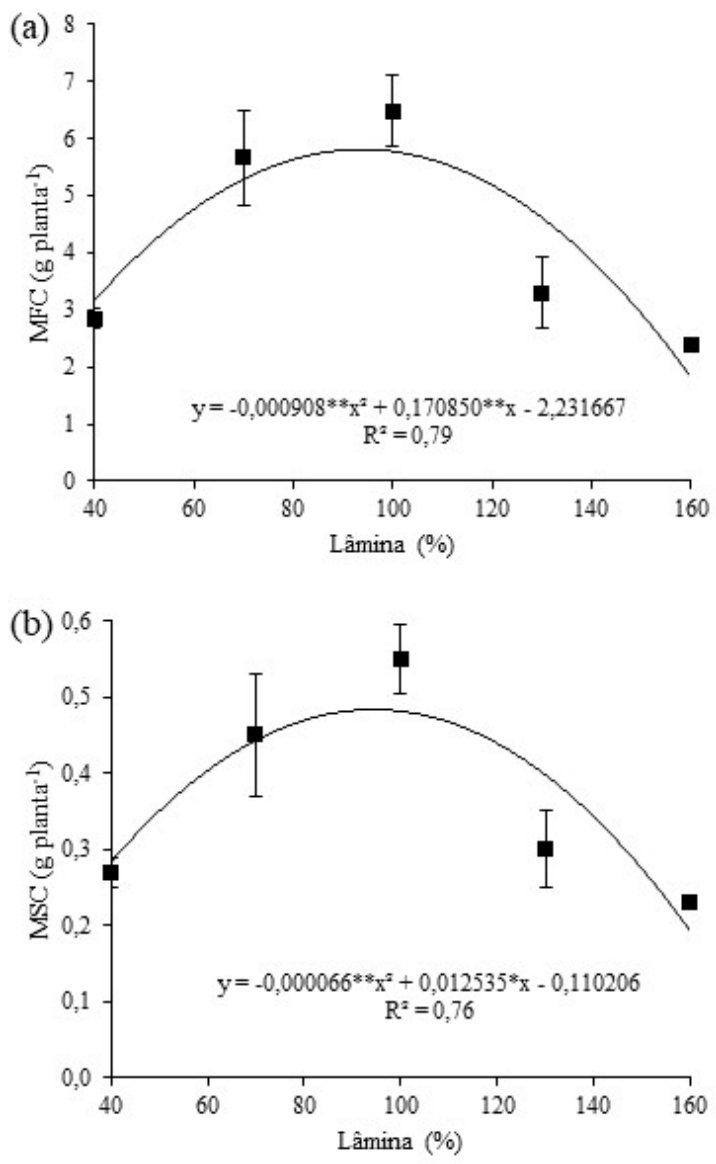

Figura 3. Massa fresca (a) e seca (b) do caule de plantas de jambu em função da lâmina de irrigação. ** significativo a $1 \%$ de probabilidade; * significativo a $5 \%$ de probabilidade pelo teste t-Student.

Figure 3. Stalk fresh matter (a) and stalk dry matter (b) of jambu crop as a function of irrigation depth. ${ }^{* *}$ significant at $1 \%$ probability; * significant at $5 \%$ probability by Student's t-test.

Para características como a massa fresca e seca do caule das plantas, apesar de o DH não ter sido influenciado pelas variações do teor de água no substrato, verificam-se alterações quanto ao acúmulo de biomassa do caule frente às oscilações de umidade do substrato, o que sugere também que estas variáveis são afetadas pelas mesmas forças que limitam o crescimento das folhas durante o estresse (Taiz et al., 2017).

A disponibilidade hídrica é um fator importante para a fotossíntese e o crescimento das plantas (Taiz et al., 2017). Fátima et al. (2018) reforçam esse ponto, pois, ao analisarem as trocas gasosas da alface cultivada em regimes hídricos distintos, observaram que plantas que receberam $50 \%$ da evapotranspiração real apresentaram menor condutância estomática que, consequentemente, reduziu a fotossíntese, o que refletiu na redução do seu crescimento.
Quanto a MFR e MSR, observou-se a formação de modelos quadráticos, em que lâminas de irrigação estimadas de 94,90 e $95,38 \%$, respectivamente, atingiram valores máximos de 3,84 e 0,32 g planta $^{-1}$ (Figura 4).

Lâminas de irrigação excessivas provocam aumento de umidade em torno da raiz da planta, o que dificulta o arejamento, causando anomalias fisiológicas, além de provocar a lixiviação dos nutrientes presentes no solo (Lima Junior et al., 2012). Condições de baixa concentração de oxigênio no solo promovem rotas fermentativas. Nessa condição, a glicólise torna-se a principal fonte de energia da planta, ocasionado maiores taxas de degradação de carboidratos para manter a sobrevivência celular (Taiz et al., 2017), o que provoca, caso ocorra por períodos prolongados, baixo rendimento da cultura, alterações no padrão de repartição da massa seca entre órgãos da planta e modificações no balanço hormonal (Carpinski et al., 2013). Neste trabalho foi observado este efeito, visto que nos tratamentos com lâminas superiores à capacidade de campo, as raízes se desenvolveram superficialmente devido ao excesso de água e houve menor desenvolvimento da parte aérea e da raiz em relação a tratamentos que não encharcaram o solo, como exposto na Figura 5.
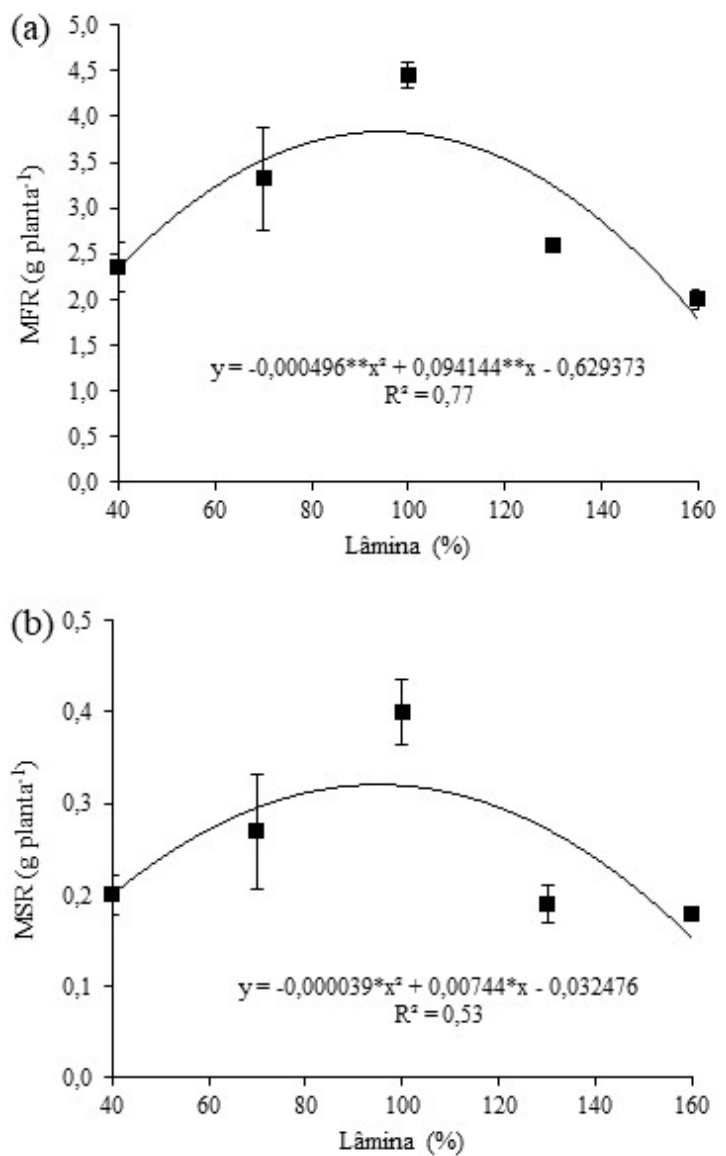

Figura 4. Massa fresca (a) e seca (b) da raiz de plantas de jambu em função da lâmina de irrigação. ** significativo a $1 \%$ de probabilidade; * significativo a $5 \%$ de probabilidade pelo teste t-Student.

Figure 4. Root fresh matter (a) and root dry matter (b) of jambu crop as a function of irrigation depth. ${ }^{* *}$ significant at $1 \%$ probability; $*$ significant at $5 \%$ probability by Student's t-test. 


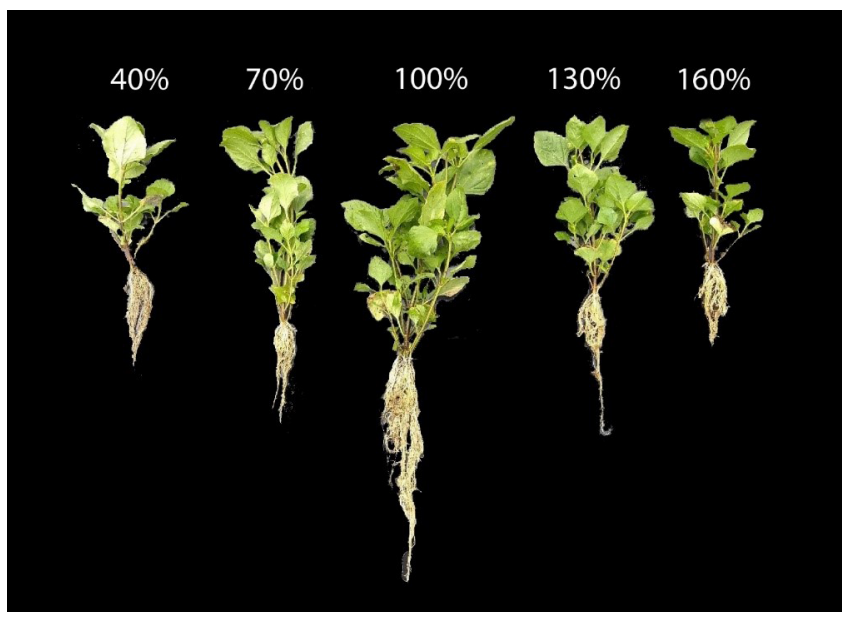

Figura 5. Desenvolvimento de plantas de jambu submetidas a diferentes lâminas de irrigação aos 47 dias após a semeadura.

Figure 5. Development of jambu plants submitted to different irrigation depths at 47 days after sowing.

Quanto a MFI, verificou-se que a disponibilidade hídrica proporcionou taxas significativas de acúmulo atingindo valor máximo estimado de $1,0 \mathrm{~g}_{\text {planta }}{ }^{-1}$ utilizando lâminas de $100,9 \%$ da capacidade de campo (Figura 6). Conforme observado nas demais variáveis analisadas neste trabalho, houve redução de MFI com aplicação de lâminas de irrigação acima da capacidade de campo do substrato.

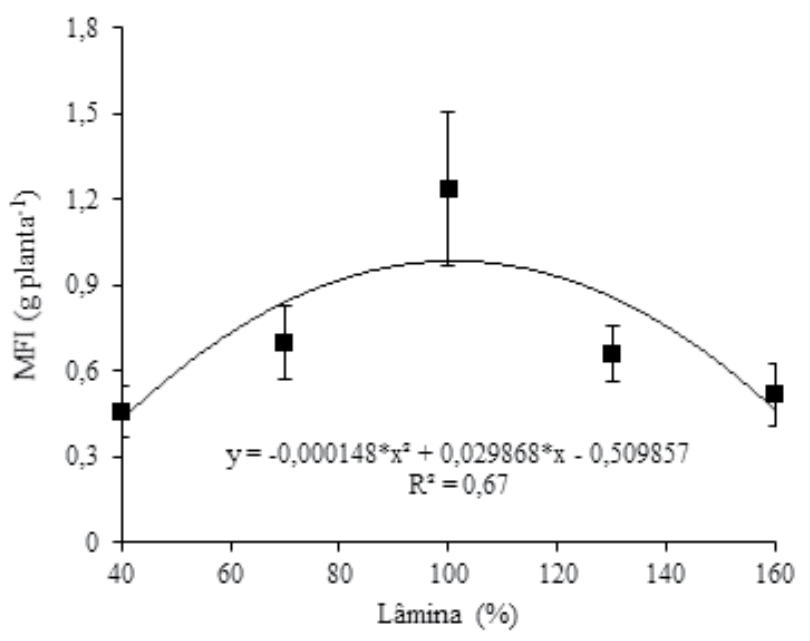

Figura 6. Massa fresca de inflorescências de plantas de jambu em função da lâmina de irrigação. ** significativo a $1 \%$ de probabilidade; * significativo a $5 \%$ de probabilidade pelo teste t-Student.

Figure 6. Inflorescence fresh matter of jambu crop as a function of irrigation depth. **significant at $1 \%$ probability; *significant at $5 \%$ probability by Student's t-test.

Reduções no crescimento e desenvolvimento da cultura sob baixa e alta disponibilidade hídrica também foram observadas para outras Asteraceae, como a mil-folhas (Alvarenga et al., 2018), a camomila (Aleman et al., 2016) e a alface (Fátima et al., 2018). Em geral, a primeira ação de uma planta frente ao déficit hídrico é o fechamento estomático, que por sua vez causa redução da taxa de fotossíntese devido a redução da absorção de $\mathrm{CO}_{2}$ (Marenco et al., 2014). Isso pode ocasionar, se for uma situação de estresse persistente, reduções na capacidade reprodutiva das plantas, fato este observado no presente trabalho, em que valores extremos (40 e 160\%) da capacidade de campo resultaram nas menores respostas.

A EUA apresentou comportamento divergente das demais variáveis analisadas, sendo explicada por uma função linear decrescente. A maior eficiência observada foi na lâmina de $40 \%(9,61 \mathrm{~mm})$ da capacidade de campo, apresentando EUA de $0,82 \mathrm{~g}$ planta $^{-1} \mathrm{~mm}^{-1}$, seguida pela lâmina de $70 \%(35,59 \mathrm{~mm})$ que obteve EUA de $0,57 \mathrm{~g}_{\text {planta }}^{-1} \mathrm{~mm}^{-1}$ e a lâmina de $100 \%(172,68 \mathrm{~mm})$ que obteve EUA de $0,33 \mathrm{~g} \mathrm{planta}^{-1} \mathrm{~mm}^{-1}$. Em outra análise, quando se eleva a capacidade de campo de $40 \%$ para $100 \%$ (controle), observa-se uma redução de eficiência de $59,8 \%$. Lâminas acima de $100 \%$ da capacidade de campo resultaram em valores de EUA próximos de zero (Figura 7).

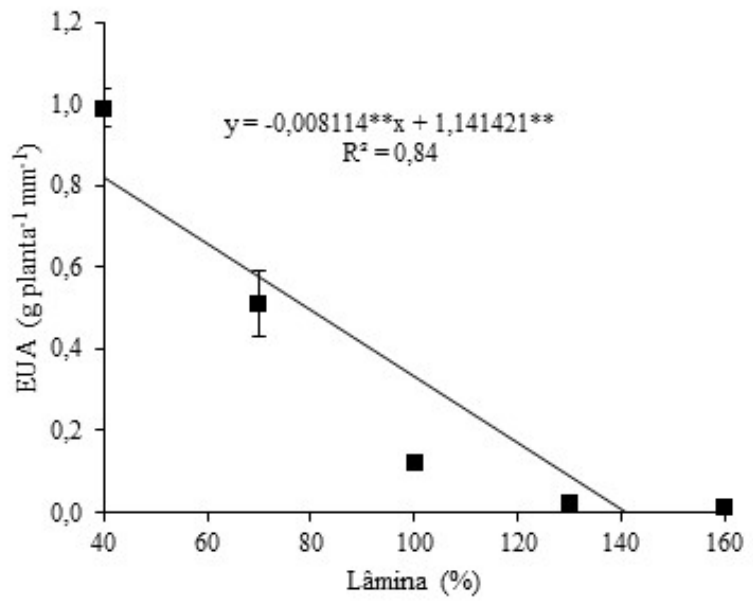

Figura 7. Eficiência do uso da água de plantas de jambu em função da lâmina de irrigação. ** significativo a $1 \%$ de probabilidade; * significativo a $5 \%$ de probabilidade pelo teste t-Student.

Figure 7. Water use efficiency of jambu crop as a function of irrigation depth. $* *$ significant at $1 \%$ probability; $*$ significant at $5 \%$ probability by Student's t-test.

Valeriano et al. (2016) obtiveram o mesmo comportamento linearmente decrescente com o aumento da lâmina de irrigação cultivando alface americana, sendo que a menor lâmina obteve maior valor na eficiência do uso da água. Da mesma forma, Nunes et al. (2017) obtiveram produtividade de água decrescente com o aumento da lâmina de irrigação em alface americana, no qual destacaram que este efeito é decorrente da redução na taxa de aproveitamento da água pela cultura, devido as perdas de água que ocorrem à medida que se aumenta as lâminas de irrigação.

De forma semelhante, Fátima et al. (2018), constataram que houve maior transpiração e eficiência no uso da água em plantas submetidas a $50 \%$ em relação a $100 \%$ da evapotranspiração atual, o que pode indicar que houve uma adaptação das plantas de alface, com maior eficiência de extração de água pelas raízes.

Neste trabalho, foi observado que a menor lâmina total aplicada ( $40 \%$ da capacidade de campo) obteve o maior uso eficiente da 
água, contudo, promoveu redução na produção de raiz e parte aérea, se comparada ao tratamento controle (100\%). Além disso, essa baixa quantidade de água aplicada $(9,61 \mathrm{~mm})$ sugere que a cultura do jambu apresenta tolerância ao déficit hídrico.

Com base nos resultados, observa-se que o aumento da produtividade de água depende de vários fatores como a qualidade do material genético, práticas eficientes de manejo de água e de práticas agronômicas (Brito et al., 2012). Desta forma, o mais recomendado é aumentar a eficiência da lâmina que proporcionou as melhores respostas das variáveis morfológicas analisadas ( $100 \%$ da capacidade de campo) por meio da aplicação da lâmina de forma parcelada ao longo do dia, com o intuito de reduzir perdas, evitar estresse hídrico e manter níveis ótimos de umidade no solo (Sousa et al., 2000).

\section{Conclusões}

As melhores respostas para as variáveis analisadas foram obtidas com lâminas de $100 \%$ da capacidade de campo, o que representa consumo médio de água de $6,4 \mathrm{~mm} \mathrm{dia}^{-1}$. $\mathrm{O}$ aumento de lâminas de irrigação reduz linearmente a eficiência do uso da água.

\section{Referências}

ARAÚJO, W. F.; SOUZA, K. T. S.; VIANA, T. V. A.; AZEVEDO, B. M.; OLIVEIRA, G. A. Rendimento e eficiência do uso da água pela alface em função da lâmina de irrigação. Caatinga, Mossoró, v. 23, n. 4, p. 115-120, 2010.

AVIZ, W. L. C.; LIMA JUNIOR, J. A.; SILVA, A. L. P.; GOMES, R. F.; SOUZA, R. O. M.; SANTOS, H. C. A.; OLIVEIRA, P. D. Productivity of jambu (Acmella oleracea) using different soil water tensions and nitrogen rates under greenhouse condition. Australian Journal of Crop Science, Brisbane, v. 13, n. 3, p. 360-366, 2019.

ALEMAN, C. C.; MARQUES, P. A. A.; PACHECO, A. C. Chamomile production using supplementary irrigation and organic fertilization in sandy soils. Revista Caatinga, Mossoró, v. 29, n. 2, p. 313-319, 2016.

ALVARES, C. A.; STAPE, J. L.; SENTELHAS, P. C.; GONÇALVES, J. L. M.; SPAROVEK, G. Köppen's climate classification map for Brazil. Meteorologische Zeitschrift, Stuttgart, v. 22, n. 6, p. 711-728, 2013.

ALVARENGA, I. C. A.; PACHECO, F. V.; ALVARENGA, A. A.; BERTOLUCCI, S. K. V.; PINTO, J. E. B. P. Growth and production of volatile compounds of yarrow (Achillea millefolium L.) under different irrigation depths. Anais da Academia Brasileira de Ciências, Rio de Janeiro, v. 90, n. 4, p. 3901-3910, 2018.

BARBOSA, A. F.; CARVALHO, M. G.; SMITH, R. E.; SABAA-SRUR, A. U. O. Spilanthol: occurrence, extraction, chemistry and biological activities. Revista Brasileira de Farmacognosia, v. 26, p. 128-133, 2016.

BORGES, L. S.; GOTO, R.; LIMA, G. P. P. Índices morfo-fisiológicos e produtividade de cultivares de jambu influenciadas pela adubação orgânica e mineral. Bioscience Journal, Uberlândia, v. 30, n. 6, p. $1768-1778,2014$.

BRITO, L. T. L.; CAVAlCANTI, N. B.; SILVA, A. S.; PEREIRA, L. A. Produtividade da água de chuva em culturas de subsistência no semiárido pernambucano. Engenharia Agrícola, Jaboticabal, v. 32, n. 1 , p. 102-109, 2012.
CARPINSKI, M.; SANTOS, R. F.; ROSA, H. A.; BASSEGIO, D.; SILVEIRA, L.; TOMASSONI, F. Sensibilidade da alface americana sob nível freático. ACTA Iguaçu, Cascavel, v. 2, n. 4, p. 55-64, 2013.

FÁTIMA, R. T.; JESUS, E. G.; GUERREIRO, A. C.; ROCHA, J. L.A.; BRITO, M. E. B. Crescimento e trocas gasosas em alface cultivada sob regimes hídricos e adubação fosfatada. Revista Brasileira de Agricultura Irrigada, Fortaleza, v. 12, n. 3, p. 2683-2891, 2018.

FERREIRA, D. F. Sisvar: a computer statiscal analysis system. Ciência e Agrotecnologia, Lavras, v. 35, n. 6, p. 1039-1042, 2011.

FURLANI, P. R.; SILVEIRA, L. C. P.; BOLONHEZI, D.; FAQUIM, V. Cultivo hidropônico de plantas. Campinas: Instituto Agronômico, 1999. 52p. (Boletim Técnico 180).

GUSMÃO, M. T. A.; GUSMÃO, S. A. L. Jambu da Amazônia (Acmella oleracea): características gerais, cultivo convencional, orgânico e hidropônico. Belém: Edufra, 2013.

HOMMA, A. K. O.; SANCHES, R. S.; MENEZES, A. J. E. A.; GUSMÃO, S. A. L. Etnocultivo do jambu para abastecimento da cidade de Belém, Estado do Pará. Amazônia: Ciência e Desenvolvimento, Belém, v. 6, n. 12, p. 125-141, 2011.

HOMMA, A. K. O. Extrativismo vegetal na Amazônia: história, ecologia, economia e domesticação. In: HOMMA, A. K. O.; SANCHES, R. S.; MENEZES, A. J. E. A.; GUSMÃO, S. A. L (ed.). Etnocultivo do jambu para abastecimento da cidade de Belém, no Estado do Pará. Brasília, DF: Embrapa, 2014. p. 329-343.

KLAR, A. E.; VILLA NOVA, N. A.; MARCOS, Z. Z.; CERVELLINI, A. Determinação da umidade do solo pelo método das pesagens. Anais da Escola Superior de Agricultura Luiz de Queiroz, Piracicaba, v. 23, p. 16-30, 1966.

KELLER, J.; KARMELI, D. Trickle irrigation design parameters. Glendora: Rain Bird Sprinkler Manufacturing Corporation, 1975.

LIMA JUNIOR, J. A.; PERREIRA, G. M.; GEISENHOFF, L. O.; VILAS BOAS, R. C.; SILVA, W. G.; SILVA, A. L. P. Produtividade da alface americana submetida a diferentes lâminas de irrigação. Semina: Ciências Agrárias, Londrina, v. 33, n. 1, p. 2681-2688, 2012.

MANTOVANI, E. C. Avalia: programa de avaliação da irrigação por aspersão e localizada. Viçosa: Editora UFV, 2001.

MARENCO, R. A.; ANTEZANA-VERA, S. A.; GOUVÊA, P. R. S.; CAMARGO, M. A. B.; OLIVEIRA, M. F. O.; SANTOS, J. K. S. Fisiologia de espécies florestais da Amazônia: fotossíntese, respiração e relações hídricas. Revista Ceres, Viçosa, v. 61, n. 7, p. 786-789, 2014.

NUNES, K. G.; COSTA, R. N. T.; CAVALCANTE JÚNIOR, J. A. H.; ARAÚJO, D. F. Comportamento da alface-americana sob diferentes doses de composto orgânico e lâminas de irrigação. Irriga, Botucatu, v. 22, n. 1, p. 167-176, 2017.

SAMPAIO, I. M. G.; HENDGES, A. R. A. A.; LIMA NETO, B. P. GUIMARÃES, M. A. Adubação de cobertura. In: GUIMARÃES, M. A.; OLIVEIRA, A. B.; DOVALE, J. C (ed.). Manutenção de hortas: práticas culturais e aspectos a serem considerados. Fortaleza: Expressão Gráfica, 2016. p. 35-49.

SAMPAIO, I. M. G.; GUIMARÃES, M. A.; LEMOS NETO, H. S.; MAIA, C. L.; VIANA, C. S.; GUSMÃO, S. A. L. Pode o uso de mudas agrupadas e a maior densidade de plantio aumentar a produtividade 
de jambu? Amazonian Journal of Agricultural and Environmental Sciences, Belém, v. 61, p. 1-8, 2018.

SAMPAIO, I. M. G.; GUIMARÃES, M. A.; LEMOS NETO, H. S.; MAIA, C. L.; VIANA, C. S.; GUSMÃO, S. A. L. Recipientes e densidades de semeadura combinadas com o tempo na produção de mudas de jambu. Amazonian Journal of Agricultural and Environmental Sciences/Revista de Ciências Agrárias, Belém, v. 62, p. 1-10, 2019.

SILVA, F. C.(Ed.). Manual de análises químicas de solos, plantas e fertilizantes. Brasília, DF: Embrapa Informação Tecnológica, 2009.

SILVA, V. D.; QUEIROZ, S. O. P. Manejo de água para produção de alface em ambiente protegido. Irriga, Botucatu, v. 18, n. 1, p. 184-199, 2013.

SILVA, L. C.; SAMPAIO, I. M. G.; BITTENCOURT, R. F. P. M.; ARAUJO, M. R.; FIGUEIREDO, S. P. R.; GUSMÃO, S. A. L.; COSTA, A. S. Influence of temperature on the germination and root size of
Acmella oleracea (L.) R. K. Jansen. RevistaAgro@mbiente, [s. l.], v. 14, p. 1-10, 2020.

SOUSA, V.F.; COÊLHO, E. F.; ANDRADE JUNIOR,A. S.; FOLEGATTI, M. V.; FRIZZONE, J. A. Eficiência do uso da água pelo meloeiro sob diferentes frequências de irrigação. Revista Brasileira de Engenharia Agrícola e Ambiental, Campina Grande, v. 4, n. 2, p. 183-188, 2000.

SOUZA, R. O. R. M.; PANTOJA, A. V.; AMARAL, M. A. C. M; PEREIRA NETO, J. A. Cenário da agricultura irrigada no Estado do Pará. Irriga, Botucatu, v. 17, n. 2, p. 177-188, 2012.

TAIZ, L.; ZEIGER, E.; MØLLER, I. M.; MURPHY, A. Fisiologia e desenvolvimento vegetal. 6 ed. Porto Alegre: Artmed, 2017.

VALERIANO, T. T. B.; SANTANA, M. J.; OLIVEIRA, A. F.; MACHADO, L. J. M. Alface americana cultivada em ambiente protegido submetida a doses de potássio e lâminas de irrigação. Irriga, v. 21, n. 3, p. 620-630, 2016.

Contribuição dos autores: Camila Duane Correa Gaia contribuiu com o planejamento, a execução e avaliação do experimento, na redação e discussão do artigo; Italo Marlone Gomes Sampaio contribuiu com a condução do experimento, a análise estatística, a discussão e revisão do artigo; Mariele dos Santos Araújo contribuiu com o planejamento, a execução e a avaliação do experimento; Jéssica Mariana Coelho Magalhães contribuiu na execução e avaliação do experimento; Raquel Giselli Assis Rosário contribuiu na execução e avaliação do experimento; Rodrigo Otávio Rodrigues de Melo Souza contribuiu com o planejamento e a idealização da hipótese.

Agradecimentos: À Universidade Federal Rural da Amazônia, em especial ao Instituto de Ciências Agrárias pelo apoio na execução do experimento e ao Professor Dr. Sérgio Antônio Lopes de Gusmão pela concessão das sementes de jambu. À Coordenação de Aperfeiçoamento de Pessoal de Nível Superior (CAPES) pela concessão da bolsa de mestrado acadêmico, Código de Financiamento 001, à primeira autora. À fundação Amazônia de Amparo a Estudos e Pesquisas (Fapespa) pela concessão da bolsa de doutorado acadêmico, ICAAF n ${ }^{\circ}$ 009/2017, ao segundo autor.

Fontes de financiamento: Não houve fonte de financiamento.

Conflito de Interesse: Os autores declaram não haver conflito de interesse. 